great importance in the major movements of the atmosphere, and that he must include with $N$ a term $-2 \omega \frac{d S}{d t}$, where $S$ is the area of the projection of the circuit on the equatorial plane and $\omega$ is the angular velocity of rotation. $\mathrm{He}_{\theta}$ did this in 1901, and pointed out the fundamental deduction that a circuit acquires cyclonic or anticyclonic circulation according as it contracts or expands.

From this time, for the next twenty years, Bjerknes devoted his energies to the problem of approximate integration of the equations of motion of the atmosphere (and the ocean) as a necessary preliminary to a practical scientific method of forecasting weather. In this he had the assistance first of J. W. Sandström and then of many other collaborators, notably $\mathrm{Th}$. Hesselberg, and from 1906 he received financial assistance for his investigations from the Carnegie Institution of Washington. There resulted "Dynamical Meteorology and Hydrography", a treatise designed to present in an ordered and rational form the principles and the practical aids to the development of meteorology and hydrography from the point of view of a mathematical physicist. The treatise was planned in three volumes; but only two were completed and issued, in 1910 and 1912. It emphasized the importance of a universal co-ordinated system of units and included the proposal, first put forward in 1906, to use absolute units of pressure, and introduced the terms 'bar' (megadyne per $\mathrm{cm} .{ }^{2}$ ) and 'millibar' as the practical units for hydrography and meteorology respectively. The millibar has now become established throughout the world in meteorology and aviation, though not yet in physical laboratories, still wedded to the mercury inch and mercury millimetre. The treatise included also the first explicit statement of the important result that the distance between contour lines on an isobaric surface in the atmosphere is an inverse measure of the geostrophic wind, independent of the density of the air. This has been the main factor in influencing meteorological services to use contours on isobaric surfaces instead of isobars on geopotential surfaces in the practical application of upper air observations.

Bjerknes had left Stockholm for Christiania in 1907 , and five years later he went to direct the new Geophysical Institute at Leipzig. $\mathrm{He}$ gathered around him a band of workers and initiated two series of publications; one of actual synoptic situations and the other of special researches, notably those by Hesselberg and Sverdrup, and, in later years, of Bergeron and Swoboda. The First World War took away his ten German assistants-half of them were killed-and in 1917 he left Leipzig for Bergen. He had already, in a lecture in London in 1910, emphasized the value of charts of stream lines in revealing lines of convergence. Their further application, begun at Leipzig and continued at Bergen, led to the development of frontal and air. mass meteorology, including the polar front and the structure of cyclones. These have played an out. standing part in meteorology in the past thirty years. Bjerknes freely acknowledged the contribution of Bergeron, Solberg, and his son, J. Bjerknes, to this development; but he was himself the architect of the building and the inspirer of the workmen. In 1920 he and Helland Hansen arranged a meeting in Bergen with British meteorologists, including Sir Napier Shaw and Dr. L. F. Richardson, and the discussions were renewed in 1921 at a meeting of the International Upper Air Commission, of which Bjerknes was president. 'The enthusiasm of the 'Bergen' School was infectious and inspiring.

In 1926 Bjerknes left Bergen, where the work was continued by his pupils and whither meteorologists from all over the world were drawn. He returned to his former ehair at Christiania (now Oslo), and with the collaboration of Solberg, J. Bjerknes, Bergeron and Godske completed and published the threevolume treatise on "Hydrodynamics and the Applications to Meteorology", issued in 1933-34, which stands as his permanent memorial. He retired in 1932, but continued to take an active part in international meteorology. He presided over the fruitful meetings of the Association of Meteorology of the International Union of Geodesy and Geophysics at Edinburgh in 1936. He lived in Oslo during the German occupation, sad but courageous. In 1946 he paid his last visit to England, when he and Prof. C. Størmer were the two delegates from Norway to the Newton Tercentenary Celebrations of the Royal Society. In the summer of 1948 he was looking forward cheerfully to his winter ski-ing.

Bjerknes was dignified in manner, in appearance and in his presentation of his scientific work; but with his dignity he combined a certain modesty and an unfailing attraction and stimulus to younger men. Through them his influenee on meteorological development has been outstanding in the meteorological services of all nations.

Bjerknes married, in 1893, S. H. Bonnevie, whose gracious and warm-hearted hospitality at the Bergen meetings of 1920 and 1921 was a fitting, well-remembered counterpart to the scientific enthusiasm of Bjerknes and their son, Prof. J. Bjerknes, to whom meteorologists throughout the world will wish to tender their respectful sympathy in his loss.

E. GOLD

\section{Mr. H. St. J. K. Donisthorpe}

Horace St. John Kelly Donisthorpe, who died on April 22, was the sole survivor of the 'great five' of myrmecology. In the period between 1850 and 1950 immense advances were made in the study of ants. These embraced practically every field: the re-organization of their taxonomy, the study of their distribution, their life-history, polymorphism, and behaviour. Thousands of papers were produced and more than ten thousand new species were described during this period. The inspiration behind all this work was the existence of five great students of ants, Auguste Forel in Switzerland, Wasman in Holland, Wheeler in America, Emery in Germany, and Donisthorpe in Britain. Each one was an amateur.

Donisthorpe published his first paper on ants in 1908. Since then he has published more than three hundred papers reporting his studies on ants. His book, "British Ants", first published at his own expense in 1915 and re-published considerably enlarged and amended in 1927, is still the book to which anyone seeking knowledge about the ants of Britain must turn.

To-day, Donisthorpe is remembered chiefly as a taxonomist. He always sought to encourage people to study ants, and he would go to any lengths to help them to make their studies more accurate and worth while. In his early days, he spent much time studying the behaviour of ants, especially their slavemaking and the way in which the queen ants (females) found new colonies. 
At the same time, most of Donisthorpe's knowledge of ant behaviour was learnt in the field in the manner of the old school: it was learnt by his wanting to know more about their habits because he wished to collect more specimens or obtain the queens.

Personally, Donisthorpe was a great character. The last time I saw him he recounted again with pride how in his twenties he had swum across the Rhine near Heidelberg, a feat which, so it was said, no one had achieved before. Lately, he persevered in his attempts to continue going to the British Museum (Natural History) each day, or at least for some days each week, until his death.

Derek Wragge Morley

\section{NEWS and VIEWS}

Mathematics at Birmingham :

Prof. G. N. Watson, F.R.S.

THE chair of mathematics in the University of Birmingham will be vacated at the end of the present session by Prof. George Neville Watson, who has held it since 1918. Prof. Watson, who was born in 1886 and educated at St. Paul's School and Trinity College, Cambridge, was senior wrangler in 1907 and became a Fellow of Trinity in 1910. He was elected to the Royal Society in 1919 and became successively president of the Mathematical Association in 1932 and of the London Mathematical Society in 1933. $\mathrm{He}$ is a Gold Medallist of the Danish Royal Academy of Sciences, and among other distinctions is an honorary LL.D. of the University of Edinburgh. Prof. Watson's name first became known by several important memoirs on asymptotic series, which were followed by a series of papers in which he found asymptotic expressions and approximations for all sorts of functions by the method of steepest descents (a term coined by him and which is now standard). About 1917 many of the ablest mathematicians were attempting to sum a difficult series which had presented itself in connexion with the diffraction of wireless waves around the earth. Prof. Watson solved the problem, and went on to study the transmission of electric waves when it is assumed that the earth is surrounded by a concentric conducting layer. Other celebrated researches were concerned with general transforms and the Rogers-Ramanujan identities. Prof. Watson is well known to all honours students of mathematics by two books, "Modern Analysis" (written in conjunetion with Sir Edmund Whittaker) and the "Theory of Bessel Functions", perhaps the most important single work that has ever been written on the analysis of functions.

Dr. R. A. Rankin

Prof. Watson is to be succeeded by Dr. Robert A. Rankin, at present lecturer in mathematics in the University of Cambridge. From Fettes College Dr. Rankin went up in 1934 to Cambridge, where he is now a Fellow of Clare College; he was a wrangler in 1936, and took a distinction in Part 3 of the Mathematical Tripos the following year. He started on a research career in the field of the theory of numbers, and five papers appeared before the end of 1940. Shortly after the outbreak of the Second World War, groups of research students were recruited to defence departments to expand their limited effort, and Dr. Rankin was among the first team to join the relatively new Projectile Development Establishment of the Ministry of Supply, formed to develop rockets. The theory of numbers was scarcely applicable, but his quality as a mathematician was soon obvious, first in day-to-day develop. ment problems of rocket weapons, and later in a more fundamental way. He became a leading member of
Prof. L. Rosenhead's ballistics branch and was to put on a firm foundation the mathematics of rocket theory, particularly that of spinning rockets. This work has been published (Phil. Trans. Roy. Soc., A, 241,457 ; 1949) and places on record a paper comparable to that of Fowler, Gallup, Lock and Richmond on the spinning shell, which was the fruit of research of the First World War. Since then Dr. Rankin has returned to the theory of numbers, and has already to his credit a long list of research papers on the differences between consecutive prime numbers and the properties of the coefficients of modular forms. More recently he has turned his attention to problems in linear forms and has discussed such problems as the packing of convex bodies and associated problems in the geometry of numbers.

\section{United States Office of Naval Research}

Dr. EMANUEL R. PIORE has recently been appointed deputy and chief scientist of the United States Office of Naval Research, in succession to Dr. Alan T. Waterman, now director of the National Science Foundation. Dr. Piore graduated in physics from the University of Wisconsin in 1930 and took his Ph.D. there in 1936. During 1938-42 he was engineer in charge of the television laboratories of the Columbia Broadcasting System, interesting himself in the development of colour television. After service during the Second World War as a senior physicist in the Navy's Bureau of Ships and then in the Navy Reserve as a lieutenant-commander, he joined the Office of Research and Inventions (later to become the Office of Naval Research) in 1946 as head of the electronics branch, and since 1949 he has been deputy for natural sciences. Dr. Piore's previous post at the Office of Naval Research has been filled by Dr. Randal N. Robertson, formerly director of the Physical Sciences Division of the Office. Dr. Robertson will be responsible for research in the earth, physical and mathematical sciences. He went to the Office of Naval Research in 1946 from the Radiation Laboratory of the Massachusetts Institute of Technology, where he had been engaged in war-time research and development of airborne radar bombing systems.

\section{"Science News"}

SEVERAL recent articles have commented on the outstanding advances in science and particularly in physics made during the past fifty years and on the profound effect these advances have had on our everyday life. The importance, both to industry and to science, of informing, without undue delay, as wide a public as possible of the investigations being undertaken by men of science, of the results obtained and of their implications has been correctly emphasized. Whereas the scientific periodicals of the various professional bodies have for long catered for the specialists and research workers, it is only com- 